\title{
Pregnancy planning and risk behaviours - a survey of women's experiences in selected European countries
}

\author{
Małgorzata Lesińska-Sawicka', Małgorzata Nagórska² \\ ${ }^{1}$ Faculty of Humanities, University of Applied Sciences in Koszalin, Poland \\ ${ }^{2}$ Institute of Experimental and Clinical Medicine, Medical Faculty, University of Rzeszow, Poland
}

Lesińska-Sawicka M, Nagórska M. Pregnancy planning and risk behaviours - a survey of women's experiences in selected European countries. Ann Agric Environ Med. 2018; 25(1): 95-99. doi: 10.5604/12321966.1235162

\begin{abstract}
Pregnancy, a special period in a woman's life, should be preceded by proper preparation: a positive attitude to procreation, selection of optimum time for becoming pregnant, starting prevention of neural tube defects, restriction of the use of drugs, smoking, etc. The aim of this study was to determine the effect of pregnancy planning and antenatal classes on the use of stimulants during pregnancy. The study group included 877 women living in 7 European countries, and their experiences of planning pregnancy and substance abuse during pregnancy were investigated. In about a half (50.3\%) of respondents the pregnancy was planned. The highest percentage of mothers who planned pregnancy was recorded in Poland and Bulgaria (about 76\%). By contrast, in Germany the proportion of mothers who planned pregnancy was the lowest (46.2\%). Surprisingly, they became pregnant despite very frequent use of birth control (96.7\%). On average, $17.3 \%$ of respondents disclosed that they drank alcohol or coffee, smoked cigarettes or used psychoactive drugs during pregnancy. Among women who did not plan to be pregnant, the use of stimulants was recorded more often. However, pregnancy planning only slightly inclined women to stop the consumption of stimulants. Attendance at antenatal classes did not have any significant effect on the use of stimulants.
\end{abstract}

Key words

pregnancy planning, substance abuse, European countries, antenatal classes, stimulants

\section{INTRODUCTION}

Pregnancy is a special period in a woman's life, requiring appropriate preparations that should begin as soon as she starts to plan to become a mother. This not only covers the mental attitude to motherhood, selection of optimum time for pregnancy or starting prevention of neural tube defects, but also ceasing or reducing the consumption of stimulants, which may pose a serious problem to the future mother.

Newborn health is the result of many factors, both genetic and environmental, affecting the mother and baby before and during pregnancy. It is therefore important to eliminate as soon as possible, or at least reduce, the influence of harmful factors on the developing foetus, including stimulants. Publications on this subject provide numerous examples of the negative influence of alcohol, nicotine, and excessive use of coffee and medicines during pregnancy. A baby in the mother's womb develops and grows very dynamically, it is therefore much more susceptible to undesirable effects of medications or chemicals than an adult.

The placenta fully transfers alcohol to the baby's circulation, and after 40-60 minutes its level in foetal blood is the same as in the mother's blood. The baby developing in the uterus does not have a fully developed liver, thus it is longer exposed to the toxic effects of alcohol [1]. Numerous consequences of alcohol consumption by pregnant women are known, starting from Foetal Alcohol Syndrome (FAS) to

Addres for correspondence: Małgorzata Lesińska-Sawicka, Faculty of Humanities, University of Applied Sciences in Koszalin, Poland

E-mail: safkowa@op.pl

Received: 12 October 2013; accepted: 17 March 2015; first published on March 2017 its less pronounced variation, FAE (Foetal Alcohol Effect), Alcohol-Related Birth Defects (ARBD), Alcohol-Related Neurodevelopmental Disorder (ARND), increased risk of cryptorchidism in male foetuses [2] and intrauterine death of the foetus [3]. The strength of the effect of alcohol on a foetus is still controversial and there is no evidence on a safe dose of alcohol that can be consumed during pregnancy, although not all countries have a strict recommendation against alcohol consumption by pregnant women, e.g., in the UK [4].

Information on smoking in the perinatal period shows its influence on the birth status of a newborn, including: low birth weight, which may be linked with an illness, disability, early death or sudden infant death syndrome (SIDS) [5]. Babies of smoking mothers are more susceptible to infant and early childhood diseases, as compared to babies whose mothers did not smoke during pregnancy. Researchers of this issue do not know precisely which components of tobacco smoke are most harmful and this issue is therefore still very controversial. However, the transfer of toxins through the placenta results in reduced blood flow and reduced oxygen level in the baby's circulatory system. Additionally, smoking mothers are at a greater risk of placenta praevia, miscarriages, or premature rupture of membranes [6].

Consumption of caffeine during pregnancy and its harmful effect on the developing foetus are still not fully explained, and consequently often ignored. Results of some studies show that consumption of low doses of caffeine during pregnancy do not pose any risk to the foetus. It should be remembered, however, that caffeine, present in coffee, tea, some soft drinks, chocolate and some medicines, is a substance easily passing through the placenta to the foetus. 
It can increase foetal heart rate, reduce blood flow and iron absorption through the placenta, possibly increasing the risk of anaemia. Some studies suggest that drinking more than 7 cups of coffee daily may increase the risk of stillbirth, premature birth, miscarriage or low birth weight of the baby. Therefore, numerous experts recommend reducing the intake of coffee and drinks containing caffeine whenever possible, as consumption of even small amounts of caffeine during pregnancy seems to increase the risk of low birth weight of the baby [7].

Most medicines administered to the mother penetrate to the baby's circulation through the placenta. In the body of a developing baby some chemical substances reach higher levels than in the mother's body. One of the reasons why this situation is dangerous is the fact that babies do not have fully developed mechanisms for the metabolism of medicines. Safety of medicine use during pregnancy is described by safety categories, which, however, are usually provided without any additional description. The effect of medicines on a foetus depends also on the time when they are used. It is assumed that till the seventh day after fertilisation the risk is low, as dividing cells are not yet differentiated and have a high regenerative potential. The highest risk related to the sideeffects of medicines is between the tenth and ca. sixtieth day of pregnancy, during embryogenesis. In the second and third trimester, the nervous and reproductive systems develop and toxic effects of medicines in that period may adversely affect sexual development and result in neurological disorders in the baby.

\section{OBJECTIVE}

The study was aimed at determining the effect of pregnancy planning and antenatal classes on the use of stimulants during pregnancy.

\section{METHODS}

The presented results are part of a research project (crosssectional study) carried out among European women, by using a special questionnaire developed by the first author. The aim of this research project is to understand the factors influencing the decisions of women originating from different countries (in terms of nationality) and the behaviours and feelings associated with being a mother.

Although the tendency to move away from religion in general or the lessening of religious attitudes is increasing in Europe, in this study it was taken as a criterion for differentiating the social context of nationality. The selected countries include: Belgium, Bulgaria, Germany (northern lands), Italy, the Netherlands (northern provinces), Poland and Ukraine, with the prevailing religions: Protestantism, Catholicism and Orthodox Christianity. Another criterion taken into account was the fertility rate in recent years in each country. Among Orthodox countries, the fertility rate was high in Ukraine and low in Bulgaria, among Catholic countries, it was low in Poland and high in Italy and Belgium, and among Protestant countries, it was high in the Netherlands and low in Germany.

The study was conducted in 2011-2013 and involved 877 women having children aged up to about 10 years, living in the 7 European countries. The first author deliberately used random sampling. Respondents' participation in the study involved an anonymous self-completion questionnaire (in a closed envelope), which was distributed mainly in primary schools (Belgium, the Netherlands), kindergartens (Bulgaria, Germany, Poland), and health care centres (Italy, Ukraine). The completed questionnaires were collected by headmasters, nurses or mothers whose children attend kindergartens. Usually, the completed questionnaires were returned to the first author by post, but some participants sent them directly to an e-mail address (4.9\% of returned answers).

Statistical analysis was based on quantitative presentation of social and psychosocial phenomena - in this case, measuring the experiences of European women - but the study results were also supplemented with a qualitative analysis of participants' statements.

The study protocol and procedures were approved by the Committee of Bioethics at the Regional Chamber of Physicians in Szczecin, nortrhern Poland. Written informed consent was obtained from all participating women.

\section{STATISTICAL ANALYSIS}

The analysis was performed using Statistica 10 PL software. The results were presented as a frequency Table and descriptive statistics. The significance of relationships between categorical variables was analysed by Pearson's $\chi^{2}$ test, and contingency coefficients were calculated.

\section{RESULTS}

The participants' average age during the study was 33.7 years. Their average age at sexual initiation was 16.7 years, but they were first pregnant, on average, at the age of 25.3 years (Tab. 1). As many as $75.0 \%$ of participants became

Table 1. Characteristics of study participants $(n=877)$

\begin{tabular}{|c|c|c|c|c|c|c|c|}
\hline \multirow[b]{2}{*}{ Characteristic } & \multicolumn{3}{|c|}{ Mostly Catholic } & \multicolumn{2}{|c|}{$\begin{array}{l}\text { Mostly } \\
\text { Orthodox }\end{array}$} & \multicolumn{2}{|c|}{$\begin{array}{c}\text { Mostly } \\
\text { Protestant }\end{array}$} \\
\hline & 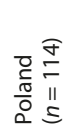 & 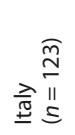 & 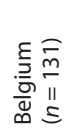 & 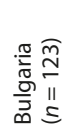 & 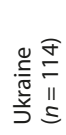 & 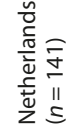 & 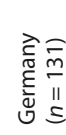 \\
\hline $\begin{array}{l}\text { Average age during the } \\
\text { study (years) }\end{array}$ & 31.7 & 36.4 & 36.8 & 30.5 & 29.2 & 37.9 & 29.6 \\
\hline $\begin{array}{l}\text { Average age at sexual } \\
\text { initiation (years) }\end{array}$ & 18.7 & 20.4 & 17.6 & 18.3 & 19.4 & 16.1 & 17.4 \\
\hline $\begin{array}{l}\text { Average age when } \\
\text { pregnant for the first time } \\
\text { (years) }\end{array}$ & 25.5 & 28.9 & 25.2 & 24.8 & 23.0 & 27.3 & 23.0 \\
\hline Pregnancy plans (\%) & 76.3 & 63.9 & 62.3 & 76.5 & 63.3 & 67.0 & 46.2 \\
\hline Use of birth control (\%) & 70.9 & 68.6 & 56.1 & 43.2 & 39.6 & 100.0 & 96.7 \\
\hline $\begin{array}{l}\text { Use of stimulants during } \\
\text { pregnancy (\%) }\end{array}$ & 15.6 & 10.2 & 22.8 & 4.3 & 12.2 & 59.3 & 1.7 \\
\hline Antenatal classes (\%) & 44.1 & 71.1 & 35.1 & 9.4 & 39.8 & 58.3 & 92.3 \\
\hline \multicolumn{8}{|l|}{ Gravidity (\%) } \\
\hline 1 pregnancy & 54.3 & 32.9 & 43.7 & 47.9 & 56.4 & 31.2 & 72.9 \\
\hline 2 pregnancies & 41.3 & 46.4 & 34.9 & 47.9 & 32.9 & 51.4 & 16.7 \\
\hline 3 pregnancies & 3.3 & 15.5 & 12.6 & 4.2 & 9.6 & 15.6 & 2.1 \\
\hline 4 pregnancies & 1.1 & 4.1 & 4.9 & - & - & 1.8 & 8.3 \\
\hline 5 pregnancies & - & - & 2.9 & - & 1.1 & - & - \\
\hline 6 pregnancies & - & 0.9 & 1.0 & - & - & - & - \\
\hline
\end{tabular}


pregnant for the first time at the optimum childbearing age, i.e. between $20-30$ years.

About half (55.0\%) of the women participating in the study became mothers at the planned moment in their lives, while for $34.0 \%$ of participants, motherhood started earlier or later than they planned. The remaining $11.0 \%$ did not think about pregnancy plans. Within the second group, about $41.7 \%$ of women had a baby earlier than they planned, while the other $58.3 \%$ became mothers later than planned. The highest percentage of mothers who planned pregnancy was recorded in Poland and Bulgaria (about 76.0\%). By contrast, in Germany the proportion of mothers who planned pregnancy was the lowest (46.2\%). Surprisingly, they became pregnant despite very frequent use of birth control (96.7\%).

On the basis of the results, it can be seen that most women planned their first pregnancy consciously, at the time that was the best for them, when they were prepared mentally and physically for the role of a mother. About $65.7 \%$ of participants planned their pregnancy and $56.6 \%$ used various methods of birth control: natural (22.6\%), pharmacological (24.1\%), mechanical (14.4\%) and chemical (5.9\%). The percentage of women not using any of the listed methods was $43.4 \%$, which is similar to the ratio of women not planning pregnancy and those who became pregnant at a different time than that planned (34.3\% and $34.0 \%$, respectively). The highest number of participants not using any methods of birth control were from Ukraine (60.4\%).

In most cases, women participating in the study did not use any stimulants. However, it is worrying that $17.3 \%$ of participants, despite pregnancy, drank alcohol or coffee, smoked cigarettes or took psychoactive drugs. Within the group of women engaged in risk behaviours during pregnancy, $7.8 \%$ disclosed that they used more than one agent harmful to a baby developing in the uterus. The stimulants most often used by pregnant participants were: cigarettes $51.7 \%$, alcohol $-20.2 \%$, coffee and psychoactive drugs $-0.1 \%$ each. The remaining $20.1 \%$ of participants did not explain which stimulants they used.

Among the participants who did not plan their pregnancy, the use of stimulants was more frequent than among women planning motherhood (Tab. 2). A significant relationship was found between pregnancy planning and the use of stimulants during pregnancy $\left(\chi^{2}=5.83 ; p=0.0157\right)$, but the relationship was not strong (Pearson's $C_{\text {adj }}=0.09$ ).

Table 2. Pregnancy planning and use of stimulants during pregnancy by study participants $(n=877)$

\begin{tabular}{lcc}
\hline \multirow{2}{*}{ Group } & \multicolumn{2}{c}{ Use of stimulants } \\
\cline { 2 - 3 } & Yes & No \\
\hline Women who planned pregnancy $(n=580)$ & $102(17.6 \%)$ & $478(82.4 \%)$ \\
\hline Women who did not plan pregnancy $(n=297)$ & $65(21.9 \%)$ & $232(78.1 \%)$ \\
\hline
\end{tabular}

Among the participants engaged in risk behaviours during pregnancy, the highest number was in the Netherlands (51.3\%), Belgium (23.7\%), Ukraine (12.2\%) and Poland (11.8\%). The relationship between the use of stimulants and the participant's country of origin was significant $\left(\chi^{2}=27.89\right.$; $p=0.00336$ ), but not strong (Pearson's $C_{\text {adj }}=0.19 ; \varphi=0.19$ ).

Statistical analysis showed a relationship between the use of stimulants and gravidity (number of pregnancies). The more times a woman was pregnant, usually the more often she was engaged in risk behaviours (here, the use of stimulants): During the first pregnancy, $13.9 \%$ participants used stimulants, the second $-14.4 \%$, the third $-30.5 \%$, and the fourth $-17.8 \%$. The obtained results of statistical analysis indicate a significant relationship between the use of stimulants and number of pregnancies $\left(\chi^{2}=14.39 ; p=\right.$ 0.0446 ), with a low strength of the relationship (Pearson's $C_{\text {adj }}=0.14 ; \varphi=0.14$ ).

Only $36.6 \%$ participants declared they attended antenatal classes. The conducted statistical analysis indicated a significant relationship between participation in antenatal classes and pregnancy planning $\left(\chi^{2}=3.88 ; p=0.0488\right)$, but a low strength of the relationship (Pearson's $C_{\text {adj }}=0.06$ ). As many as $83.2 \%$ of women attending antenatal classes used no stimulants during pregnancy, compared to $59.8 \%$ of women not attending this form of education. The conducted statistical analysis, however, showed no statistical relationship between participation in antenatal classes and use of stimulants. Women participating in the study who did not attend antenatal classes most often came from Belgium (62.3\%) and Poland (56.8\%).

Dominant religion apparently does not have any effect on substance abuse during pregnancy in individual countries. However, religion seems to affect the use of birth control, which was most frequent (about 95-100\%) in Protestant countries, moderate (about 55-70\%) in Catholic countries, and the lowest (about 40\%) in the countries where Orthodox Christianity prevailed. Besides, the average age at sexual initiation was slightly lower in the countries where Protestantism was dominant.

\section{DISCUSSION}

An increasing number of women consciously decide to have a baby at the time optimal for them, to that aim using both natural birth planning methods and increasingly improved contraception. Among respondents from 18 European countries participating in the Bayer Schering Pharma study on birth control methods, conducted by the Gesellschaft für Konsumforschung (Society for Consumer Research) in November and December 2009, 62\% of European women covered by the study confirmed they planned the first pregnancy [8]. Such a high percentage of planned pregnancies is also confirmed by the presented results, where $65.7 \%$ respondents indicated baby planning.

Although women's awareness of procreation issues and preparation for motherhood increases and conscious motherhood is increasingly discussed, the problem of stimulant use during pregnancy is still significant in all European countries. Taking substances harmful for a baby, either consciously, intended or due to unconscious negligence, is called prenatal maltreatment [9] and should be strongly exposed to increase society's awareness of their harmful effect on the baby.

The observed risk behaviours of pregnant women in Europe was the motivation to show that despite the common opinion about dependence of woman's role on religion and culture, some activities are the same in different cultures and nations, although their frequency varies. For this reason, the religious views of individual women were not investigated; therefore, the observed differences between countries may be unconnected with differences in the dominant religion in those countries. In the future, it would be advisable to 
take into account also correlations between religious views and parental attitudes, as the correlations may help explain the differences in the frequency of risk behaviours among pregnant women in various cultures and religions.

Risk behaviours are actions harmful to one's health, which often are initiated unconsciously, but dangerous in their consequences. The use of psychoactive substances by pregnant women is particularly risky, as the substances affect the not only the health of the mother, but also, above all, the baby developing in the uterus, with all the consequences mentioned above. During intrauterine life, the characteristics of the phenotype of an individual are formed [10]. Although the effect of the environment on phenotypic changes has not been sufficiently recognized, the opinion is uncontested that exposure of the foetus to hazardous agents transmitted by the organism of the mother induces changes in gene expression (epigenetic), which decide about predisposition of the organism to chronic diseases after birth and in adulthood [11].

Among risk behaviours of pregnant women, the current study focuses on smoking, alcohol and coffee consumption, and the use of unprescribed drugs, including psychoactive substances. Only a very few respondents listed drugs and/or coffee among the stimulants they used, while many others did not specify which stimulants they used. Therefore, only these risk behaviours jointly with other stimulants listed by some respondents could be analysed: alcohol and tobacco. However, in future surveys, different types of stimulants should be distinguished and analysed separately.

In most cases, the women were aware they should stop consumption of alcohol when pregnant, due to resulting hazards to the developing baby [12], but they often found this very difficult. W. Szychta, M. Skoczylas and T. Laudański reviewed publications on the harmfulness of alcohol consumption and smoking by pregnant women, showing that in selected populations there was a varying percentage of pregnant women drinking alcohol [13]. Results of their metaanalysis are also confirmed by the results of the presented study. The highest percentage of pregnant women drinking alcohol and smoking in this study was among respondents from the Netherlands, Belgium and Poland. In published statistical data, the prevalence of tobacco smoking by pregnant women also varies widely between countries: $20 \%$ in Poland [14] and Japan [15], about 17\% in Australia and Canada [16.18], and 30-35\% in Spain [17]. Published studies indicate that smoking habits change significantly during pregnancy. Pregnant women limit or cease smoking, using their condition as an opportunity to stop becoming engaged in behaviours posing a risk to their health and to their babies. A Canadian study showed that $14.4 \%$ of respondents did not stop smoking while pregnant, but $7.8 \%$ started a successful struggle with this habit [18]. It is worrying that pregnant women exposed to smoking at home more often smoke in pregnancy and less often decide to discontinue the habit in association with becoming pregnant [19]. Besides, women who abuse alcohol, less often decide to desist from smoking during pregnancy [20].

Another worrying issue is the use of medicines during pregnancy. Researchers in this field report that $5-10 \%$ of women abuse medicines, while during pregnancy $5.5 \%$ take medicines prohibited for that condition [21]. In the presented study, only a low percentage of respondents disclosed that they used psychoactive drugs during pregnancy $(0.1 \%)$. However, it must be remembered that statements do not necessary reflect the actual situation, as mothers may be unwilling to disclose the truth, even in an anonymous questionnaire. It is noteworthy that women who planned pregnancy reported slightly less often the use of stimulants during pregnancy (Tab. 2).

The available published results do not show any significant influence of the knowledge presented during antenatal classes on the use of stimulants during pregnancy. Nevertheless, the review of publications on antenatal classes conducted by M.L. Koehn, and the guidelines of the National Institute for Health and Clinical Excellence, indicate that women participating in this form of preparation for parenthood had a better knowledge on responsibility for health than women who did not participate $[22,23]$.

Publications on the use of psychoactive agents during pregnancy show that it is a problem of all nations worldwide. Therefore, an increased influence on women who are pregnant or plan motherhood, as well as on immediate members of their families to minimise the use of stimulants during pregnancy, would be worth considering. The perinatal period seems to be a good time for combating habits and avoidance of risk behaviours.

With open borders, frequent migrations and easy relocation, the development of a common approach of healthcare providers to the discussed issue seems to be advisable. Substance abuse during pregnancy is a global problem and only common multi-faceted actions can limit its frequency.

It is also worth adding that procreative decisions are of importance in terms of medicine and health, as they are related to the functioning of the human body subject to the control of institutions related to scientific medicine, as well as to sociology. Those biological processes and functioning of the human body are underlain by living conditions, organisation and functioning of social life, and culture [24]. Therefore, the pro-health behaviour of women deciding to become mothers is based both on medical and social aspects.

The efforts undertaken by public health authorities should focus on the education of people at reproductive age about the hazardous effect of smoking and other addictions on the health of children before and after birth. Women at reproductive age should be encouraged in various ways to discontinue risk behaviours in association with the planning of pregnancy and during pregnancy [25].

\section{CONCLUSIONS}

1. On average, $17.3 \%$ of respondents disclosed that they used stimulants (cigarettes, alcohol, coffee and/or psychoactive drugs) during pregnancy. The proportion varied between countries from 1.7\% in Germany to 59.3\% in the Netherlands.

2. Pregnancy planning seems to have only a slight effect on substance abuse by pregnant women. Women who planned pregnancy reported the use of psychoactive agents and other stimulants less frequently (17.6\%) than women who did not plan it (21.9\%).

3. The use of stimulants during pregnancy, only to a small extent depends on the number of previous pregnancies and the country of origin, and does not depend on participation in antenatal classes during pregnancy. The strength of relationships in the tests was estimated as low. 
4. Public health authorities should focus on the education of people at reproductive age about the effect of stimulants on child health before and after birth. Health professionals should encourage and help women at reproductive age to stop substance abuse before or during pregnancy.

\section{Acknowledgments}

The authors express their thanks to Sylwia Ufnalska, MSc, MA, for assistance in editing the manuscript.

\section{REFERENCES}

1. Salmon J. Fetal alcohol spectrum disorder: New Zealand birth mothers' experiences. Can J Clin Pharmacol. 2008; 15: 191-213.

2. Damgaard IN, Jensen TK, Petersen JH, et al. Cryptorchidism and maternal alcohol consumption during pregnancy. Environ Health Perspect. 2007; 115: 272-7.

3. Kesmodel U, Wisborg K, Olsen SF, et al. Moderate alcohol intake during pregnancy and the risk of stillbirth and death in the first year of life. Am J Epidemiol. 2002; 155: 305-12.

4. Alcohol consumption and the outcomes of pregnancy. Royal College of Obstetricians and Gynaecologists Statement. 2006, No. 5.

5. Wisborg K, Kesmodel U, Henriksen T. A prospective study of smoking during pregnancy and SIDS. Arch Dis Child. 2001; 84: 203-206.

6. Jaddoe VW, Troe EJ, Hofman A, et al. Active and passive maternal smoking during pregnancy and the risks of low birthweight and preterm birth: the Generation R Study. Paediatr Perinat Epidemiol. 2008; 22: 162-71.

7. Bakker R, Steegers EAP, Obradov A, et al. Maternal caffeine intake from coffee and tea, fetal growth, and the risks of adverse birth outcomes: the Generation R Study. Am J Clin Nutr. 2010; 91: 1691-1698.

8. Pan European FC Study 2009 - Bayer Schering Pharma research on the contraceptive practices, conducted in November-December 2009. http://www.hivportalen.se/narallabarnarvalkomna/Documents/ SRHR_Den_oonskade_graviditeten_Bente_Traeen_101125.pdf.

9. Suter M, Ma J, Harris AS, Patterson L, Brown KA, Shope C, Showalter L, Abramovici A, Aagaard-Tillery KM. Maternal tobacco use modestly alters correlated epigenome-wide placental DNA methylation and gene expression. Epigenetics. 2011; 6(11): 1284-1294.

10. Suter M, Abramovici A, Aagaard-Tillery K. Genetic and epigenetic influences associated with intrauterine growth restriction due to in utero tobacco exposure. Pediatr Endocrinol Rev. 2010; 8: 94-102.

11. Suter M, Bocock P, Showalter L, Hu M, Shope C, McKnight R, et al. Epigenomics: maternal high-fat diet exposure in utero disrupts peripheral circadian gene expression in nonhuman primates. FASEB J. 2011; 25: 714-26.

12. Alvik A, Haldorsen T, Groholt B, et al. Alcohol consumption before and during pregnancy comparing concurren and retrospective reports. Alcohol Clin Exp Res. 2006; 30: 510-5.

13. Szychta W, Skoczylas M, Laudański T. Spożywanie alkoholu i palenie tytoniu przez kobiety w ciąży - przegląd badań [Alcohol consumption and tobacco smoking by pregnant women: a review]. Perinatologia, Neonatologia i Ginekologia 2008; 1(4): 309-313.

14. Kalinka J. Ocena roli wybranych środowiskowych czynników ryzyka ograniczonego wzrostu płodu oraz porodu przedwczesnego przy zastosowaniu wskaźników biologicznych i biomarkerów ekspozycji [Evaluation of the role of selected environmental risk factors of low birth weight and premature birth by using biological indices and exposure biomarkers]. Lódź: Folia Medica Lodziensia 2006; 33/S1: 5-151.

15. Kaneita Y, Tomofumi S, Takemura S, Suzuki K, Yokoyama E, Miyake T, Harano S, Ibuka E, Kaneko A, Tsutsui T, Ohida T. Prevalence of smoking and associated factors among pregnant women in Japan. Prev Med. 2007; 45: 15-20.

16. Mohsin M, Bauman AE. Socio-demographic factors associated with smoking and smoking cessation among 426.344 pregnant women in New South Wales, Australia. BMC Public Health. 2005; 5: 138.

17. Millar WJ, Hill G. Pregnancy and smoking. Health Rep. 2004; 15: 53-56.

18. Connor SK, McIntyre L. The sociodemographic predictors of smoking cessation among pregnant women in Canada. Can J Public Health. 1999; 90: 352-355.

19. Yoon PW, Rasmussen SA, Lynberg MC, Moore CA, Anderka M, Carmichael SL, et al. The National Birth Defects Prevention Study. Public Health Rep. 2001; 116: 32-40.

20. Lesińska-Sawicka M, Waśkow M. Palenie papierosów wśród kobiet w okresie okołoporodowym [Tobacco smoking in the perinatal period]. Pielegniarstwo XXI 2009; 1-2(26-27): 89-94.

21. Morse B, Gehshan S, Hutchins E. Screening for Substance Abuse During Pregnancy: Improving Care, Improving Health. Arlington, VA: National Center for Education in Maternal and Child Health 1997.

22. Koehn ML. Childbirth education outcomes: an integrative review of the literature. Journal of Perinatal Education 2002; 11(3): 10-19.

23. National Collaborating Centre for Women's and Children's Health, Commissioned by the National Institute for Health and Clinical Excellence. Pregnancy and complex social factors: A model for service provision for pregnant women with complex social factors, Royal College of Obstetricians and Gynaecologists 2010.

24. Woźniak Z. Socjomedyczne aspekty funkcjonowania rodziny [Sociomedical aspects of family function]. Poznań: Centralny Program Badań Podstawowych 1990.

25. Wojtyła A, Goździewska M, Paprzycki P, Biliński P. Tobacco-related Foetal Origin of Adult Diseases Hypothesis - population studies in Poland. Ann Agric Environ Med. 2012; 19(1): 117-128. 